\title{
Erratum to: Extended T-index models for glacier surface melting: a case study from Chorabari Glacier, Central Himalaya, India
}

\author{
Indira Karakoti $^{1} \cdot$ Kapil Kesarwani $^{1} \cdot{\text { Manish } \text { Mehta }^{2} \text { • D. P. Dobhal }}^{1}$
}

Published online: 30 March 2016

(C) Springer-Verlag Wien 2016

\section{Erratum to: Theor Appl Climatol}

DOI 10.1007/s00704-016-1753-6

Section 3.3.2, in Line 8: humid-temperature should be read humid-temperate

Section 4.1, second column, $4^{\text {th }}$ paragraph, in line 2: Fig. 5(a) should be read as Fig. 5(b)

In Table 4: the first row i. e. (26 Jul-10Jun 2049.836 .2 24.7) is inserted by mistake. The correct table is as below.

Table 4 Measured and Simulated melt for 2012

\begin{tabular}{lllll}
\hline Date & $\begin{array}{l}\text { Observed net } \\
\text { fortnightly } \\
\text { melting }(\mathrm{cm})\end{array}$ & $\begin{array}{l}\text { Simulated net fortnightly } \\
\text { melting }(\mathrm{cm})\end{array}$ & & \\
\cline { 3 - 5 } & & T-index model & Model 1 & Model 2 \\
\hline 11 Jun - 25 Jun & 15.0 & 63.7 & 9.4 & 8.7 \\
26 Jun - 10 Jul & 60.0 & 61.5 & 49.5 & 51.4 \\
11 Jul - 25 Jul & 34.0 & 66.5 & 41.4 & 39.9 \\
26 Jul - 10 Aug & 60.0 & 65.7 & 72.3 & 69.5 \\
11 Aug - 25 Aug & 62.0 & 63.7 & 75.0 & 73.2 \\
26 Aug - 10 Sep & 112.0 & 58.8 & 82.7 & 79.8 \\
11 Sep - 25 Sep & 55.0 & 53.7 & 66.8 & 71.3 \\
26 Sep - 10 Oct & 91.0 & 37.0 & 82.6 & 89.9 \\
11 Oct - 25 Oct & 17.0 & 5.4 & 22.6 & 24.2 \\
\hline
\end{tabular}

The online version of the original article can be found at http://dx.doi.org/ 10.1007/s00704-016-1753-6.

Indira Karakoti

indira_ntl@yahoo.co.in

1 Centre for Glaciology, Wadia Institute of Himalayan Geology, Dehradun 248001, India

2 Wadia Institute of Himalayan Geology, Dehradun 248001, India 